\title{
An Association between Breaking Voice and Grief-related Lyrics in Country Music
}

\author{
BRANDON PAUL \\ Ohio State University, School of Music \\ DAVID HURON ${ }^{[1]}$ \\ Ohio State University, School of Music
}

\begin{abstract}
Thirty-one instances of breaking voice were identified in recordings of Country songs. Song lyrics were rated by independent judges for grief-related content in both breaking-voice songs and matched control songs. Judges compared pairs of lyrics for target and control songs at four context sizes: entire sets of lyrics, single stanzas, isolated lines, and individual words where the breaking voice occurs. An association was found between instances of breaking voice and grief-related content for individual words but not for the larger lyrical contexts. The results are consistent with the idea that breaking voice provides an affective cue conveying, evoking or highlighting grief.
\end{abstract}

Submitted 2009 November 25; accepted 2010 March 29.

KEYWORDS: music, emotion, lyrics, Country music, grief, breaking voice, falsetto

BREAKING voice is a distinctive vocalization that can be observed in several styles of vocal music around the world. In Western music, it can be heard occasionally in operatic performance, but it is more commonly heard in Country music (Fox, 2004; Urban, 1991; Wise, 2007). Breaking voice is characterized by a rapid alternation between falsetto and modal vocalizations. In contrast to modal (or chest) phonation, falsetto phonation arises when the vocalis muscle is relaxed and the main vibrational energy is concentrated at the margins of the vocal folds (Švec and Peš́k, 1994, p.98). When crying, it is common to feel a distinctive "lump" in one's throat - a constriction that contributes to an unstable switching between modal and falsetto phonation. The result is a "breaking" or "cracking" voice, in which both modes of phonation may occur within a single vowel. Typically, this break involves moving from falsetto to modal voice, but the break can also involve moving from modal to falsetto voice. During puberty, the vocal folds thicken and lengthen in both males and females - but more dramatically in the case of males (Harries et al., 1998). As growth continues, there may be a period of chronic instability in which a boy's voice changes unpredictably between modal and falsetto phonation resulting in a characteristic awkward pubescent male voice. The resemblance of such breaking voice to crying or weeping probably accounts for the acute embarrassment often experienced by adolescent speakers.

In the case of weeping, the physiology of breaking voice remains obscure. Frick $(1985$, p. 420) has noted a general tendency for facial muscles to contract during grief, and that a similar contraction may occur in the larynx. This contraction might explain the sensation of a "lump" in the throat as well as the tendency for the pitch to shift upward from modal to falsetto voice.

In the research literature it is common for grief and sadness to be conflated. Sadness is a low arousal emotion characterized by low heart rate, shallow respiration, slumped posture, loss of appetite, sleep, reduced engagement with the world, and rumination. By contrast, grief is a high arousal emotion characterized by high heart rate, erratic respiration, flushed face, tears, nasal congestion, laryngeal constriction, and vocalizing (from quiet sobbing to loud wailing). Periods of psychic pain commonly involve alternating episodes of (quiet) sadness and (louder) grief. It is this confusion between sadness and grief that appears to account for the conflicting reports related to vocal production. Sadness is linked to lower vocal pitch (e.g. Scherer \& Scherer, 1981), whereas grief is linked to higher vocal pitch (e.g. Costanzo et al., 1969); see Frick (1985, p. 417) for further discussion concerning the apparently conflicting research reports. 
In the case of music, a number of studies have observed the relationship between affective cues in speech and in music. Aaron Fox (2004) has written extensively regarding sadness and grief in American Country music. Similarly, Christine Yano (2002) has provided detailed ethnographic descriptions of musicinduced weeping, sadness and nostalgia in the distinctive Japanese genre known as Enka. Other researchers have also carried out important studies related to lament, such as Margarita Mazo's (1994) studies of the acoustic characteristics of Russian lament and Greg Urban's work on Brazilian ritual wailing (1991). In the case of sadness, a number of recent studies have tested predictions arising from affective prosody research. Western music in the minor mode is lower in overall pitch than music in the major mode, has smaller average intervals sizes (Huron, 2008), is slower in overall tempo (Post \& Huron, 2009), exhibits a quieter dynamic level (Turner \& Huron, 2008), and is associated with darker timbres (Schutz et al., 2008).

In this study we will focus on a single grief-related vocal feature, namely breaking voice. In brief, we report on a correlational study in which we relate instances of breaking voice to the affective content in the corresponding lyrics. To anticipate our results, we will see a significant association between instances of breaking voice and the grief-related content of the associated sung word.

\section{HYPOTHESIS}

Formally, our hypothesis is as follows:

H1: Instances of breaking voice in Country songs are associated with grief-related content in the lyrics.

In order to test this hypothesis we asked Country music fans for examples of sound recordings in which the singer's voice "breaks." After confirming the instances of voice breaks, the lyrical content was compared with the lyrics of matched control songs. Breaking voice recordings were paired with other recordings on the same album by the same singer without the voice breaking.

\section{METHOD}

\section{Informants/Survey}

Seven Country music fans were recruited and asked to identify songs in which the singer's voice "breaks." Each informant was provided with a CD containing three examples identified by the authors as exemplars of breaking voice. Each excerpt on the sample CD consisted of just a single phrase containing the voice break. Typically, the provided sound exemplars were about eight seconds in duration. Over a period of two months, the fans listened to their collections and filled out report forms identifying pieces in which the singer's voice breaks. Appendix I identifies the three exemplars of breaking voice provided for the informants. The report form is reproduced in Appendix II.

In the instructions to the informants, "breaking voice" was defined as follows:

INSTRUCTIONS:

A voice "breaks" when there is an abrupt transition from high to low - like when a young boy's voice "cracks." You will have heard this in songs sung by Merle Haggard, Dolly Parton and others.

Notice that the above description of breaking voice includes no reference to crying, weeping, or grief. Our intention was to avoid biasing informants towards sad or grief-related songs. Nevertheless, there may remain a demand characteristic in which the informants somehow inferred that we wanted them to identify sad songs. However, as we will see later in the data analysis, the results will show that there is no evidence of such a demand characteristic. In fact, we will see that the songs selected by the informants, were, if anything, less sad than the randomly selected controls. It is only at the level of individual words that the grief-related content corresponds to the moment when the breaking voice occurs.

After two months, the seven fans provided 77 instances of purported breaking voice. Although the reports did not ask for the sex of the informant, it was possible to surmise from the submitted written documents that four of the informants were female, one was male, and two were of indeterminate sex. Of the 77 purported breaking-voice instances, 71 were unique; that is, six instances were identified by more 
than one informant. Unfortunately, the authors were able to locate recordings for just 56 of the 77 identified songs.

Having secured these recordings, our next task was to confirm that the works contained appropriate instances of breaking voice. In auditing the recordings identified by the informants, the authors noted that some of the songs contained multiple instances of breaking voice while other identified recordings did not seem to exhibit any breaking voice. For example, some of the purported breaking-voice instances might be better described as mordents - rapid pitch alternations in which the voice did not seem to oscillate between modal and falsetto phonation. In addition, the authors noted that when identifying the locations of breaking-voice instances, informants tended to report the first occurrence in the recording.

Two independent judges unfamiliar with the purpose of the study were recruited and asked to confirm whether the 56 identified songs contained breaking voice. Both judges were graduate students in linguistics, familiar with vocal phonology. For those songs deemed to contain instances of breaking voice, the judges were also instructed to identify the "best" or most "prototypical" example in the song. Judges reported the specific time in the recording where they identified the best breaking voice.

Specifically, judges received the following written instructions.

\section{INSTRUCTIONS:}

In this study we are interested in "breaking" voice in country songs. A voice "breaks" when there is an abrupt transition from high to low - like when a young boy's voice "cracks." Note that a "breaking" voice will involve an alternation between normal and falsetto voice. Note that a quick pitch alternation (such as a mordent) might occur without switching between normal and falsetto voice - and these we would not regard as instances of breaking voice.

The following recordings were identified by Country music fans as containing such vocal "breaks." Your task is to make an independent judgment of whether you believe a given song contains an instance of breaking voice. For each song, please identify on the response sheet whether the song contains, in your judgment, a true "breaking" voice. For those songs you deem to contain a breaking voice, you may find that several instances occur at various points in the song. For these songs, please identify the location (time count) of what you consider the "best" example of a breaking voice. By "best," we mean the clearest or most obvious example of breaking voice.

Do you have any questions?

In addition, the judges were provided with the three recorded exemplars of breaking voice distributed to the informants.

Of the 56 musical samples identified by our Country music fans, the two linguists independently agreed that 12 songs did not exhibit breaking voice. Of the remaining 44 songs, the two judges agreed that 31 songs contained unambiguous instances of breaking voice. Accordingly, our study focused on these 31 target songs (identified in Appendix III).

Lyrics for the 31 target works were collected from Internet sources-mostly from cowboylyrics.com or songlyrics.com. These lyric collections are assembled primarily by fans who submit the lyrics, either by typing the liner notes or by transcribing the recordings themselves. In order to ensure accuracy, the experimenters proof-listened to the 31 recordings and confirmed that the actual sung lyrics matched the published lyrical texts.

\section{Control Sample}

In order to address the hypothesis, a control sample of songs was also assembled. For each identified breaking-voice song, a suitable control sample would be a randomly selected song from the same album sung by the same singer. Unfortunately, this approach can raise some practical difficulties. In some cases, performing groups employ more than one singer and it is sometimes difficult to determine which singer is singing a given song. For example, on the album Waitin' On Sundown both Kix Brooks and Ronnie Dunn sing lead vocals. From this album, an informant had identified "She's the Kind of Trouble" as an example of breaking voice. Regarding singer identity, album information may not be sufficiently detailed. One could endeavor to track down producers or other knowledgeable sources in order to confirm the singer's identity for each track. However, this approach was deemed impractical. Suppose there are two main singers in a 
group: one who frequently employs breaking voice, and the other who rarely employs breaking voice. Suppose further, that the breaking-voice singer is more apt to sing songs with greater grief-related content. If we happen to select a control song sung by the other singer, any association between grief-content and breaking voice would remain consistent with our hypothesis, even though the control piece was not truly matched for the singer's voice.

Accordingly, in selecting our control songs, our sole criterion was simply to choose another song from the same album, even though the singers might differ. An exception to this principle was made in cases where the gender of the singers differed. That is, in all cases, both the breaking-voice song and control song involved singers of the same sex from the same album.

A further potential confound relates to the ordering of songs on an album. In sequencing the tracks on an album, producers and artists may aim to create a particular narrative or emotional dynamic. For example, producers might program successive songs to create a contrasting effect; alternatively, producers might aim to link together similar works. This suggests that two successive songs may exhibit unknown correlations. Consequently, in randomly selecting the control songs, we explicitly excluded songs that immediately preceded or immediately followed the target song. This was done in order to increase data independence.

Finally, randomly selected control songs were audited to ensure that no breaking voice occurred. In the control sampling process, six such instances arose in which the randomly selected song also involved breaking voice. In these cases, another randomly selected song was sampled. Notable artists who appear to use breaking voice as a ubiquitous stylistic element include Garth Brooks, Rissi Palmer, and LeAnn Rimes.

As in the case of the target songs, lyrics for the control songs were collected either from cowboylyrics.com or songlyrics.com, and the accuracy of the lyrical texts was confirmed via prooflistening.

\section{Content Analysis}

Having identified 31 songs containing unambiguous instances of breaking voice and 31 control songs selected from the same albums, an independent group of judges was recruited to carry out a comparative analysis of the lyrics. Four different tasks were used to judge the grief-related content of the lyrics. In the first task (word judgment) judges were given pairs of words, one each from the target and control songs, and asked to judge which word was more grief-related. The word from the target song coincided with the occurrence of the breaking voice. The associated control word was a randomly selected word from the control lyrics. The control word was selected so as to maintain the same part of speech. For example, if the breaking-voice lyric was a noun, the matched control word was a randomly selected noun. Words were classified as nouns, pronouns, adjectives, verbs, adverbs, prepositions, conjunctions, or interjections. In the second task (line judgment) judges were given pairs of lines, one each from the target and control songs, and asked to judge which line was more grief-related. A "line" was defined as the text containing the target word but appearing in the published lyrics with a line break preceding and following. In the third task (stanza judgment) judges were given pairs of stanzas, one each from the target and control songs, and asked to judge which stanza was more grief-related. Once again, a "stanza" was defined according to the published song text - where a stanza was defined as a segment of text separated by blank lines from other segments. Finally, in the fourth task (whole-song judgment) judges were given the complete lyrics for the target and control songs and asked to judge which lyric contained more grief-related imagery.

Eight participants, unfamiliar with the purpose of the experiment, were recruited to make these content-related judgments. Participants were graduate students at the Ohio State University School of Music. Participants were never exposed to the recorded songs, nor were they aware of the song titles or artists: participants only examined printed lyrics. Each participant completed all four tasks. However, participants completed only a single task for each of the 31 songs. That is, a given participant never made more than one content judgment for a single song.

Judges were instructed as follows:

\section{INSTRUCTIONS:}

Your task is to make comparisons between whole songs, stanzas, lines, and words to determine which you deem to be more "grief-related." "Grief" may be defined as personal or social loss, physical pain, distress, or other negative emotion. 


\section{RESULTS}

The results are summarized in Table 1 which identifies the proportion of breaking-voice songs that were judged as having greater grief-related content in the lyrics for words, lines, stanzas, and whole lyrics. A chance level would be 50 percent. As can be seen, for three of the four conditions, participants appear to have judged the target songs as exhibiting less grief-related imagery than the control songs - opposite to our hypothesis. However, these differences are not statistically significant suggesting that they are the product of random variation (songs: $\chi^{2}=1.16, \mathrm{df}=1, p>0.05$; stanzas: $\chi^{2}=1.03, \mathrm{df}=1, p>0.05$; lines: $\chi^{2}=0.06$, $\mathrm{df}=1, p>0.05)$. Only one of the four conditions proved to be statistically significant - namely the word condition $\left(\chi^{2}=10.9, \mathrm{df}=1, p<0.05\right)$. In short, the results imply that there is a significant association between breaking voice and the grief-related content of the corresponding sung word. However, the results are not consistent with the notion that breaking voice is more likely to occur in lines, stanzas, or whole songs that exhibit more grief-related imagery.

Table 1. Number of song lyrics judged to exhibit more grief-related content. Results are shown for four contextual sizes: entire text, stanzas, lines, and words. Results are statistically significant only for the word context - consistent with the hypothesis that instances of breaking voice in Country music tend to coincide with words exhibiting greater grief-related content

\begin{tabular}{lcc}
\hline Contextual Size & Target Songs & Control Songs \\
\hline Entire Text & 26 & 36 \\
Stanzas & 27 & 35 \\
Lines & 29 & 33 \\
Words & 44 & 18 \\
\hline
\end{tabular}

\section{SUMMARY}

In this study, we examined whether the occurrence of breaking voice in a sample of Country songs is associated with grief-related content in the lyrics. Seven Country music fans provided 71 unique instances of breaking voice in commercial recordings, 31 of which were confirmed by independent auditors. Lyrics were obtained for both the identified breaking-voice songs as well as control songs selected from the same album. Eight judges assessed the relative grief content for words, lines, stanzas, and whole lyrics associated with the breaking-voice instances. The results show that breaking voice is associated with grief-related content in the lyrics of Country music songs only for the word in which breaking voice occurs. The results are consistent with the hypothesis that breaking voice is associated with grief-related lyrical content - but only at the most local level of text setting.

\section{DISCUSSION}

In many ways our results are fortuitous. Recall that in instructing our Country music fans to identify songs containing breaking voice we expressed the concern that our informants may have purposely biased their sampling toward songs that are especially sad or grief-related. However, the results in Table 1 show that the lyrics of the target songs are not biased towards grief-related imagery. In fact, the results are skewed in the opposite direction from such a bias: when assessing entire lyrics, the target lyrics were judged to exhibit less grief-related imagery than the control lyrics - although this skew is not statistically significant. Such results are not consistent with the contention that our Country music fans were influenced by a hypothetical demand characteristic that encouraged them to select sad or grief-related songs. In light of this result, we may be more confident that the significant association between breaking voice and the grief-related content of the associated word is not spurious. 
As with any empirical study, we must acknowledge several caveats when interpreting the results. First, all of our participants, including the Country music fans, the linguist-judges, and the lyric-judges were recruited from a single region, namely the state of Ohio. The results may not generalize to other parts of the United States, let alone to other cultures. Second, our study focused exclusively on recent Country music. The function of breaking voice in Country music from the early $20^{\text {th }}$ century may differ from more recent practices. For example, it is possible that early Country music employed breaking voice only for songs with explicitly "sad" content; over time, breaking voice may have evolved into a stylistic or idiomatic sound that has become representative of the Country genre in general, and is not reserved solely for sad songs. A future study might focus on possible historical or diachronic changes in the use of breaking voice in Country music.

Third, the results for Country music may not be applicable to other genres in which breaking voice is used - such as Western opera, Alpine folk song yodeling (Wise, 2007), Russian laments (Mazo, 1994), Japanese Enka music (Yano, 2002), and Brazilian ritual wailing (Urban, 1991).

Finally, breaking voice may be indicative of an "emotional" voice versus a more specifically grieving voice. Wise (2007) assumes that the intentionality of breaking-voice instances denotes an unspecified form of emotional expression or emotional significance. Urban (1991, p. 159) also notes falsetto phonation is a signal of "heightened emotional response," but does not specify a type of emotion. Breaking voice might convey several different affective cues depending on context and may not universally be related to grief.

\section{NOTES}

[1] Please address all correspondence to: David Huron, School of Music, 1866 College Road, Columbus, Ohio, 43210, U.S.A.

\section{REFERENCES}

Costanzo, F.S., Markel, N.N., \& Costanzo, P.R. (1969). Voice quality profile and perceived emotion. Journal of Counseling Psychology, Vol. 16, pp. 267-270.

Frick, R.W. (1985). Communicating emotion: The role of prosodic features. Psychological Bulletin, Vol. 97, pp. 412-429.

Fox, A. (2004). Real Country: Music and Language in Working-Class Culture. Durham, North Carolina: Duke University Press.

Harries, M., Hawkins, S., Hacking, J., \& Hughes, I. (1998). Changes in the male voice at puberty: vocal fold length and its relationship to the fundamental frequency of the voice. Journal of Laryngology and Otolaryngology, Vol. 112, pp. 451-454.

Huron, D. (2008). A comparison of average pitch height and interval size in major- and minor-key themes: Evidence consistent with affect-related pitch prosody. Empirical Musicology Review, Vol. 3, No. 2, pp. 5963.

Mazo, M. (1994). Lament made visible: A study of paramusical elements in Russian lament. In: B. Yung \& J. S. C. Lam (Eds.), Themes and Variations: Writings on Music in Honor of Rulan Chao Pian. Hong Kong: Harvard Department of Music and the Center for Chinese Studies, The Chinese University of Hong Kong, pp. 164-211.

Post, O., \& Huron, D. (2009). Music in minor modes is slower (except in the Romantic period). Empirical Musicology Review, Vol. 4, No. 1, pp. 1-9.

Scherer, K.R., \& Scherer, U. (1981). Speech behavior and personality. In: J.K. Darby, Jr. (Ed.), Speech, Evaluation in Psychiatry. New York: Grune \& Stratton, pp. 115-135. 
Schutz, M., Huron, D., Keaton, K., \& Loewer, G. (2008). The happy xylophone: Acoustic affordances restrict an emotional palate. Empirical Musicology Review, Vol. 3, No. 3, pp. 126-135.

Švec, J.G., \& Pešák, J. (1994). Vocal breaks from the modal to the falsetto register. Folia Phoneatrica et Logopaedica, Vol. 46, pp. 97-103.

Turner, B., \& Huron, D. (2008). A comparison of dynamics in major- and minor-key works. Empirical Musicology Review, Vol. 3, No. 2, pp. 64-68.

Urban, G. (1991). A Discourse Centered Approach to Culture: Native South American Myths and Rituals. Austin: University of Texas Press.

Wise, T. (2007). Yodel species: A typology of falsetto effects in popular music vocal styles. Radical Musicology, Vol. 2. http://www.radical-musicology.org.uk/2007/Wise.htm

Yano, C. (2002). Tears of Longing: Nostalgia and the Nation in Japanese and Popular Song. Cambridge: Harvard University Asia Center.

\section{APPENDIX I: EXEMPLARS OF BREAKING VOICE}

Three exemplars provided to informants as illustrations of breaking voice:

$\begin{array}{lllll}\begin{array}{l}\text { Artist } \\ \text { Patsy Cline }\end{array} & \begin{array}{l}\text { Title } \\ \text { Crazy }\end{array} & \begin{array}{l}\text { Album } \\ \text { N/A }\end{array} & \begin{array}{l}\text { Source } \\ \text { PetMilk TV/Youtube (1962) }\end{array} & \begin{array}{l}\text { Time } \\ 1: 55-2: 03\end{array} \\ \begin{array}{l}\text { Johnson Mountain } \\ \text { Boys }\end{array} & \begin{array}{l}\text { There Goes My } \\ \text { Love }\end{array} & \begin{array}{l}\text { Blue Diamond } \\ \text { Mine }\end{array} & \begin{array}{l}\text { Rounder Records CD 0293 } \\ (1993)\end{array} & 0: 26-0: 34 \\ \text { Dave Evans } & \text { Pretty Green Hills } & \text { Pretty Green Hills } & \text { Rebel Records (2006) } & 3: 09-3: 17\end{array}$

\section{APPENDIX II: SURVEY INSTRUCTIONS}

Survey instructions provided to Country fans/informants in order to collect instances of breaking voice:

We're doing research on Country music, and we're looking for your help! If you're a Country music fan, you can help with research being carried out at The Ohio State University School of Music. It's easy. All you have to do is listen to your favorite music! We're looking for as many examples as we can of a special vocal technique called "breaking voice."

A voice "breaks" when there is an abrupt transition from high to low-like when a young boy's voice "cracks". You will have heard this in songs sung by Merle Haggard, Dolly Parton and others. On the enclosed CD you can find 3 short examples of what we're talking about. The first track is from the Johnson Mountain Boys. Listen to the voice break on the word want when he says, "I don't want to be just another..." The second track is by Patsy Cline. Listen for the break on the word tryin' during "I'm crazy for tryin'..." On the last example, the voice break can be heard during the words, "I started to ask him," on the word to. This example is by Dave Evans.

As part of our research, we need to find as many examples of "breaking voice" as we can. This is why we're appealing for your help. We would like you to browse your collection of Country music. For each song in which you think there is breaking voice, please fill in the information requested on the enclosed survey sheet. If possible, we would like to have the title of the song, the name of artist, the album title, and the time (in minutes and seconds) when you think the breaking voice occurs. Please do not list the same song twice.

If you are interested in hearing about the results of our research, include your contact information when you submit your survey sheets. We'll make sure to contact you when the research project is 
finished. Once again, thank you for your participation in helping us out at The Ohio State University School of Music!

\section{APPENDIX III: BREAKING-VOICE TARGET SONGS}

Target recordings used in grief comparison tasks:

Adkins, R. (2006). If You're Going Through Hell. If You're Going Through Hell. [Compact Disc]. Nashville, TN: Curb Records.

Anderson, K. (2005). XXL. Three Chord Country and American Rock and Roll. [Compact Disc]. Pasadena, CA: Artista.

Brandt, P. (1999). Add 'Em All Up. That's The Truth. [Compact Disc]. Nashville, TN: Warner Nashville.

Brooks, G. (1992). Mr. Right. The Chase. [Compact Disc]. Hollywood, CA: Pearl Records.

Brooks, G. (1997). She’s Gonna Make It. Sevens. [Compact Disc]. Hollywood, CA: Pearl Records.

Brooks, G. (2000). Callin' Baton Rouge. In Pieces. [Compact Disc]. Hollywood, CA: Pearl Records.

Brooks, G. (2000). New Way To Fly. No Fences. [Compact Disc]. Hollywood, CA: Pearl Records.

Brooks, G. (2005). Good Ride Cowboy. The Lost Sessions. [Compact Disc]. Hollywood, CA: Pearl Records.

Brooks, K., \& Dunn, R. (1994). I'll Never Forgive My Heart. Waitin' On Sundown. [Compact Disc]. Pasadena, CA: Artista.

Brooks, K., \& Dunn, R. (1994). If That's The Way You Want it. Waitin' On Sundown. [Compact Disc]. Pasadena, CA: Artista.

Brooks, K., \& Dunn, R. (1994). You're Gonna Miss Me When I'm Gone. Waitin' On Sundown. [Compact Disc]. Pasadena, CA: Artista.

Canyon, G. (2004). Hell or High Water. One Good Friend. [Compact Disc]. Nashville, TN: Universal South.

Carroll, J. M. (2007). I Can Sleep When I'm Dead. Waitin'In The Country. [Compact Disc]. Pasadena, CA: Artista.

Cline, P. (1988). So Wrong. Patsy Cline: 12 Greatest Hits. [Compact Disc]. Nashville, TN: MCA Nashville.

Crowell, R. (1993). She's Crazy For Leaving. Rodney Crowell: Greatest Hits. [Compact Disc]. Nashville, TN: Sony Music Nashville.

Gatlin, L. (2004). Boogie and Beethoven. Live At Billy Bob's Texas. [Compact Disc]. Fort Worth, TX: Smith Music Group.

Holy, S. (2006). Brand New Girlfriend. Brand New Girlfriend. [Compact Disc]. Nashville, TN: Curb Records.

Larsen, B. (2006). I Don't Know What She Said. Rockin' You Tonight. [Compact Disc]. Nashville, TN: BNA Entertainment. 
McGraw, T. (2004). Back When. Live Like You Were Dying. [Compact Disc]. Nashville, TN: Curb Records.

Nichols, J. (2002). Old Cheyenne. Six of One Half Dozen Of the Other. [Compact Disc]. Nashville, TN: Row Music Group.

Nichols, J. (2004). Shade. Revelation. [Compact Disc]. Nashville, TN: Universal South.

Owen, J. (2006). Yee Haw. Startin’With Me. [Compact Disc]. Nashville, TN: RCA.

Palmer, R. (2007). Country Girl. Rissi Palmer. [Compact Disc]. Norcross, GA: 720 Entertainment LLC.

Rimes, L. (1998). Looking Through Your Eyes. Sittin’ On Top of the World. [Compact Disc]. Nashville, TN: Curb Records.

Sweethearts of the Rodeo. (1993). Hoping That You're Hoping. Rodeo Waltz. [Compact Disc]. Nashville, TN: Sugarhill.

Tucker, T. (1987). San Antonio Stroll. Greatest Hits. [Compact Disc]. Nashville, TN: MCA Nashville.

Turner, J. (2006). Your Man. Your Man. [Compact Disc]. Nashville, TN: MCA Nashville.

Urban, K. (2004). Homespun Love. In the Ranch. [Compact Disc]. Nashville, TN: MCA Capitol.

Walker, K. (1997). Watch This. Rumor Has It. [Compact Disc]. New York, NY: Giant Records/WEA.

Yearwood, T. (1996). It's Alright. Everybody Knows. [Compact Disc]. Nashville, TN: MCA Nashville.

Yearwood, T. 2005. Baby Don't You Let go. Jasper Country. [Compact Disc]. Nashville, TN: MCA Nashville. 